\title{
The Relationship of Brain-Tissue Loss Volume and Lesion Location to Cognitive Deficit
}

\author{
Jordan Grafman, * Andres Salazar, ${ }^{*}$ Herbert Weingartner, $\dagger$ Stephen Vance, ${ }^{*}$ and Dina Amin $\ddagger$ \\ *Vietnam Head Injury Study, Department of Clinical Investigation, Walter Reed Army Medical Center, Washington, \\ DC 20307, †Laboratory of Psychology and Psychopathology, Cognitive Studies Unit, Bethesda, Maryland 20205, \\ and $\ddagger$ The George Washington University Biostatistics Center, Bethesda, Maryland 20014
}

\begin{abstract}
We examined the relationship of preinjury intelligence, a lesionseverity variable (brain-tissue loss volume), and lesion location to the persistence of cognitive deficits in Vietnam veterans with penetrating brain wounds. Using stepwise multiple linear regression procedures, we found that preinjury intelligence predicted a significant amount of the variance on postinjury cognitive testing, being a better predictor for tests requiring a number of complementary cognitive processes (e.g., intelligence tests) than for tests measuring a specific cognitive process (e.g., face recognition). Brain-tissue volume loss was found to play a larger role when a global cognitive measure was used, but a smaller role when a specific cognitive process was measured. Finally, lesion location was shown to be a significant predictor of performance only for specific cognitive processes. Nevertheless, preinjury intelligence/education appears to play an even larger role in postinjury performance than either brain-tissue loss volume or a particular structural loss.
\end{abstract}

Lashley (1963) hypothesized that cognitive deficits following cerebral ablations are directly related to the amount of tissue ablated, irrespective of the location of that lesion. This claim has never been adequately addressed by research with human, brain-injured subjects (Eidelberg and Stein, 1974). However, the most extensive attempt to investigate the effect of localized lesions in humans was carried out by Teuber (1959) and his colleagues, who investigated the effect of penetrating missile wounds upon behavior in World War II and Korean War veterans. Early work by this group (Teuber et al., 1952) indicated that "intellectual deficits" following posterior brain lesions were generally more severe than those following anterior lesions. More refined analysis enabled Weinstein and Teuber (1957b) to specify the critical location as the left parietotemporal cortex, although they cautioned that their results were probably testspecific. In addition, when all lesion sites were considered, the

\footnotetext{
Received Jan. 29, 1985; revised July 15, 1985; accepted July 18, 1985.

The authors thank the staffs of the Neurology Service and Department of Clinical Investigation at Walter Reed Army Medical Center for their help and advice, as well as the George Washington University Biostatistics Center. For their sincere diligence, we thank all members of the Vietnam Head Injury Study (VHIS) research team, and especially Mrs. Judy Quinn for preparing this manuscript. Our deep appreciation goes to Navy Master Chief (Ret.) Herbert R. Brown for his administrative expertise and for sharing his extensive knowledge of the history of this project with us. This paper is dedicated to the memory of Dr. William F. Caveness: But for his foresight, tireless efforts, and determination, this research project would never have been possible. This study was funded by Veterans Administration Contract IGA V101 (91) M-79031-2, with the cooperation and support of the U.S. Army, Navy, and Air Force and the American Red Cross. The views expressed herein are those of the authors and not of the Department of Defense.

Correspondence should be addressed to Jordan Grafman, Ph.D., CAPT, USAF, BSC, Chief, Neuropsychology Section, Vietnam Head Injury Study, Department of Clinical Investigation, Walter Reed Army Medical Center, Washington, DC 20307-1348.

$0270-6474 / 86 / 020301-07 \$ 02.00 / 0$
}

long-term effect of a penetrating brain wound upon "general intelligence" seemed limited. Other analyses by Teuber's group (Teuber, 1959; Teuber and Liebert, 1958) demonstrated that general as well as specific effects could be observed following penetrating brain wounds. For example, in contrast to intelligence-test performance, which was primarily affected by left temporoparietal brain lesions, performance on the Hidden Figures Test was not associated with lesions to a specific lobe or hemisphere (Corkin, 1979; Teuber and Weinstein, 1956).

Teuber (1960) also considered premorbid factors in postinjury test performance. He speculated that preinjury motives and attitudes could modify postinjury recovery, but that this effect was probably restricted to patients with smaller lesions. Larger lesions or "strategically placed" lesions could interfere with the patient's abiltiy to act on his motives or to remember them. An earlier study by Weinstein and Teuber (1957a) gave no support to the hypothesis that preinjury education or preinjury intelligence level would be related to the magnitude of postinjury loss of intellectual functioning. More recent work by Newcombe (1969) and others (e.g., Black, 1974) supplemented and refined many of the above findings.

Experimental animal research has led to a more complicated picture than the one originally envisioned by Lashley in explaining lesion effects upon behavior. Among others, Nakamura and Gaz7aniga (1978) directly challenged Iashley's original hypothesis and showed it to be false. LeVere (1975) has commented on the remarkable ability of "neural centers" to exhibit a great degree of recovery of function following brain lesions. He touches upon the observation that "pre-lesion behavior patterns" are able to withstand neurologic insult and that this survival is primarily dependent on spared (presumably differentiated from the impaired) functional capacities and not "reorganization" of neural tissue. In principle, Meyer and Meyer (1977) have supported this thesis, but their studies also reveal that postinjury relearning of a selective habit is not only possible, but can be selectively facilitated by certain interventions. As Thompson et al. (1983) point out, while the issue of localization remains fundamental to research on learning and memory, it has clearly become complex and will depend, for further resolution, on interdisciplinary collaboration, ranging from psychological research to studies of learning at the level of the synapse (Cotman and Nieto-Sampedro, 1982).

Despite the interest in Lashley's hypothesis and cortical localization, there has not been an adequate comparison of the effects of lesion location, overall size of lesion, and premorbid factors upon performance on a variety of cognitive tasks in a single study in humans. We have had the opportunity to examine the relationship of total volume of brain-tissue loss, lesion location (i.e., involvement of particular brain structures), and preinjury intelligence to the persistence of cognitive deficits in Vietnam veterans with penetrating brain wounds. We hypoth- 
Table 1. Subjects with penetrating brain wounds

\begin{tabular}{|c|c|c|c|c|}
\hline & \multicolumn{2}{|c|}{ Right hemisphere lesions } & \multicolumn{2}{|c|}{ Left hemisphere lesions } \\
\hline & $\begin{array}{l}\text { Mean } \\
(N=98)\end{array}$ & SD & $\begin{array}{l}\text { Mean } \\
(N=84)\end{array}$ & SD \\
\hline Age & 37.71 & 3.27 & 37.29 & 2.57 \\
\hline Years of education & 13.20 & 2.39 & 13.20 & 2.41 \\
\hline Preinjury AFQT percentile score & 54.92 & 25.40 & 52.47 & 26.68 \\
\hline Total brain-volume loss $\left(\mathrm{cm}^{3}\right)$ & 34.63 & 41.78 & 35.04 & 37.27 \\
\hline VIQ & 105.34 & 11.68 & 98.62 & 14.16 \\
\hline PIQ & 100.58 & 12.35 & 100.41 & 13.88 \\
\hline FSIQ & 103.23 & 11.20 & 99.46 & 14.06 \\
\hline Comprehension Scale score & 12.07 & 2.66 & 10.62 & 3.33 \\
\hline Similarities Scale score & 11.31 & 2.45 & 10.17 & 2.71 \\
\hline Block Design Scale score & 9.77 & 2.78 & 10.52 & 2.73 \\
\hline VCAT: Total correct & 15.57 & 5.02 & 12.87 & 6.31 \\
\hline $\begin{array}{l}\text { Spatial Rotation corrected score } \\
\text { (hits - false positives) }\end{array}$ & 17.43 & 12.99 & 16.38 & 13.64 \\
\hline
\end{tabular}

Relevant subject characteristics and group means and standard deviations on the dependent variables (the tests are described in the text).

esized that brain-tissue loss volume would be an important predictor of performance when a "global" cognitive measure was used (e.g., an additive measure of intelligence that depends on several complementary cognitive processes), but would have a smaller role when a more specific cognitive process was tested (e.g., spatial rotation ability that depends on a cognitive process less susceptible to further fractionation). Lesion location was thought to be a significant predictor of performance only when assessing a specific cognitive process. In addition, we predicted that a preinjury estimate of intelligence [i.e., the Armed Forces Qualification Test (AFQT)] would also account for a large amount of the variance on postinjury cognitive performance, being greater for global cognitive measures representing several complementary cognitive processes, and less for tests measuring a specific cognitive process.

We conducted a retrospective pilot study (with subjects drawn from the same sample as subjects in the present study) that supported our hypotheses. For example, preinjury AFQT performance $(F=406.92, p=0.0001)$, total brain-tissue loss volume $(F=47.69, p=0.0001)$, and, to a lesser degree, left temporal-occipital whitc matter involvement $(F=15.95, p=0.0001)$ all predicted postinjury intelligence-test performance as represented by a global score (total $R^{2}=0.64$ ). However, when the more specific cognitive measure of face discrimination was tested, total brain-tissue loss volume did not contribute to the regression model $(F=0.06, p=0.81)$, and preinjury AFQT performance made a smaller contribution $(F=32.30, p=0.0001)$ to predicting performance than when the dependent variable was a general intelligence measure; involvement of several specific cortical structures (e.g., the area surrounding the right mesencephalon: $F=19.92, p=0.0001$ ) made a relatively larger contribution to the prediction of face-discrimination performance.

In this paper, we attempt to validate these findings by directly testing our hypotheses within unilateral lesion groups, using two regression models, one including and one not including a measure of preinjury intelligence.

\section{Materials and Methods}

\section{Subjects}

The Victnam Head Injury Study (VHIS) rcgistry includes 1131 men who survived penetrating brain wounds in Vietnam and on whom there are detailed medical records beginning as early as $10 \mathrm{~min}$ after injury, and continuing through Veterans Administration (VA) followup files some 5 years later (VHIS Phase I). Because of the availabilility of helicopter evacuation and the deployment of neurological surgeons close

Table 2. Pearson product correlations

\begin{tabular}{|c|c|c|c|c|c|c|c|c|}
\hline & \multicolumn{4}{|c|}{ Right hemisphere lesions } & \multicolumn{4}{|c|}{ Left hemisphere lesions } \\
\hline & \multicolumn{2}{|c|}{$\begin{array}{l}\text { Preinjury AFQT } \\
\text { percentile score }\end{array}$} & \multicolumn{2}{|c|}{$\begin{array}{l}\text { Total brain- } \\
\text { tissue loss } \\
\text { volume }\end{array}$} & \multicolumn{2}{|c|}{$\begin{array}{l}\text { Preinjury AFQT } \\
\text { percentile score }\end{array}$} & \multicolumn{2}{|c|}{$\begin{array}{l}\text { Total brain- } \\
\text { tissue loss } \\
\text { volume }\end{array}$} \\
\hline & $r$ & $p$ & $r$ & $p$ & $r$ & $p$ & $r$ & $p$ \\
\hline VIQ & 0.677 & 0.0001 & -0.027 & - & 0.562 & 0.0001 & -0.426 & 0.0002 \\
\hline PIQ & 0.522 & 0.0001 & -0.38 & 0.0003 & 0.587 & 0.0001 & -0.331 & 0.0036 \\
\hline FSIQ & 0.729 & 0.0001 & -0.198 & - & 0.615 & 0.0001 & -0.395 & 0.0005 \\
\hline Comprehension & 0.374 & 0.0002 & 0.108 & - & 0.491 & 0.0001 & -0.338 & 0.0028 \\
\hline Similarities & 0.379 & 0.0002 & 0.27 & 0.0081 & 0.42 & 0.0001 & -0.349 & 0.002 \\
\hline Block Design & 0.535 & 0.0001 & -0.304 & 0.0043 & 0.497 & 0.0001 & -0.211 & - \\
\hline VCAT & 0.349 & 0.0007 & -0.336 & 0.0013 & 0.556 & 0.0001 & -0.362 & 0.0015 \\
\hline Spatial Rotation & 0.498 & 0.0001 & -0.36 & 0.0007 & 0.617 & 0.0001 & -0.339 & 0.0031 \\
\hline
\end{tabular}


to the battlefront, most patients received neurosurgical care within a few hours (median $=6 \mathrm{hr}$ ) of injury. As a consequence, our population included many patients with such severe injuries that they probably would not have survived in previous wars. Seventy-eight percent of the injuries involved multiple lobes and $30 \%$ crossed the midline. The majority (77\%) suffered fragment wounds from explosive devices, while $16 \%$ had gunshot wounds (usually tangential). The low proportion of gunshot wounds in our population reflects the use of high-velocity rifle ammunition in Vietnam and the relatively poor survival rate following head wounds from such weapons.

Subjects selected for this study were chosen from a sample of 520 male Vietnam veterans who had recently undergone an extensive multidisciplinary reevaluation at Walter Reed Army Medical Center (WRAMC). All closed-head, bilingual, preinjury left-handed, and second head injury cases were excluded from the analysis. In addition, all subjects whose lesion crossed the midline (bilateral lesions) were also excluded. We studied 98 right-handed, right hemisphere lesion cases and 84 right-handed, left hemisphere lesion cases. Table 1 presents basic identifying data about the subjects, along with their mean test scores. The lesion groups are comparable for current age and educational level as well as for age at injury and preinjury intelligence level.

\section{$C T$ scan analysis}

Lesion location and volume were determined by a computerized tomography (CT) scan procedure/software program specifically devised for our study. CTs were done with a GE 8800 scanner in standardized $5 \mathrm{~mm}$ cuts at about $25^{\circ}$ to Reid's baseline, yielding about 24 slices per patient. Involvement of over 80 specific brain areas was coded for computer entry by the use of standard templates prepared for each slice, assigning code numbers to each area. Structures only partly involved on CT were considered to be completely involved for our analysis; thus we included potential areas of hypofunctioning tissue surrounding the $\mathrm{CT}$ defect. As a further aid in localization, a corresponding photographic, anatomic atlas was prepared by slicing a fresh-frozen specimen in situ at the same angle on a large cryotome, and photographing it at 1 $\mathrm{mm}$ intervals, which yielded over 130 brain sections. Image analysis included both a subjective morphological interpretation and a quantitative lesion analysis using a light pen to outline the affected area in each slice. Total lesion volume was then calculated from a summation of these areas on relevant slices.

We considered 26 major individual and composite structures in a mutually exclusive way so as to represent different areas of the brain. The CT scan structure descriptions were as follows: (1) cerebellum, (2) mesencephalon, (3) combined frontal cortex gray matter, (4) combined frontalparietal cortex, (5) combined temporal cortex, (6) combined temporaloccipital cortex, (7) convexity cortex, (8) mesial cortex, (9) corona radiata, (10) internal capsule, (11) external capsule, (12) insular cortex, (13) thalamus, (14) hypothalamus, (15) caudate head, (16) caudate body, (17) lentiform, (18) cortical white matter, (19) temporo-occipital white matter, (20) temporal white matter, (21) frontoparietal white matter, (22) frontal white matter, (23) corpus callosum anterior one-half, (24) corpus callosum posterior one-half, (25) genu of corpus callosum, and (26) splenium of corpus callosum.

Tests

The following measures (which were normally distributed in the headinjury group as a whole), selected from a much larger battery of neuropsychological tests, were used for this analysis:

1. Wechsler Adult Intelligence Scale (WAIS). Subjects were assessed on a composite battery of tests designed to measure intellectual abilities. Measures utilized from this test included a composite, standardized score of verbal intelligence (VIQ), a composite, standardized score of visual-spatial/performance ability (PIQ), and a general, standardized score of intelligence (FSIQ). In addition, standardized scores from three WAIS subtests were considered: (a) the Comprehension subtest, which assesses common-sense judgment, practical reasoning, and proverb understanding; (b) the Similarities subtest, which assesses verbal concept ability (i.e., analogy reasoning); and (c) the Block Design subtest, a visual-motor construction task requiring three-dimensional block reconstruction of a two-dimensional design (Matarazzo, 1972; Wechsler, 1955).

2. Verbal Concept Attainment Test (VCAT). Subjects are required to identify a set of words that best represents a concept (e.g., the subject views a card containing three rows of three words each, and is then required to choose one word from each row, the three chosen words representing a single concept). The concepts vary from concrete (e.g., names of trees) to abstract (e.g., living things). The dependent variable chosen was total number of categories accurately identified (Matthews, 1977).

3. Spatial Rotation Judgment Test. Subjects are required to choose which two out of four two-dimensional target drawings, made to resemble three-dimensional shapes, match a stimulus. Two of the designs are matches, but rotated at various deflections in a $180^{\circ}$ plane. One of the distractor designs is a mirror image of the stimulus, while the other is a totally different design. The dependent variable chosen was a correction score (hits - false positive responses) (Vandenberg and Kuse, 1978).

General cognitive measures were those dependent variables that summed cognitive performance on a variety of specific tasks. Specific cognitive measures were those dependent variables that represented relatively task-specific cognitive performance. The dependent variables we used are itemized below under their respective categories.

\section{General cognitive measures}

1. WAIS: Verbal IQ

2. WAIS: Performance IQ

3. WAIS: Full-scale IQ
Specific cognitive measures

\section{Statistical analysis}

Total brain-tissue loss volume and the previously mentioned 26 structures were used as predictors (i.e., of whether the amount of tissue loss and/or a critical lesion involving particular brain structures could predict poor test performance) in a stepwise multiple-regression procedure with the general and specific cognitive measures as dependent variables. The stepwise regression analysis was performed separately for right and left unilateral lesion groups. We used two different regression models, one unadjusted for preinjury AFQT percentile score and the second adjusted for preinjury AFQT percentile score (note that the second model always includes the preinjury AFQT percentile scorc at cach stcp of the stepwise regression procedure). A significance level of $p=0.05$ or less was required both to enter and remain in the stepwise regression procedure. This type of analysis allowed us to estimate the relative contribution of each predictor to each dependent measure's test-score variance.

\section{Results}

Table 1 lists the performance scores on the dependent variables of interest, plus the mean preinjury Armed Forces Qualification Test (AFQT) percentile score and the mean total brain-tissue loss volume. These data indicate that the two groups tested are comparable on preinjury intelligence level and on total braintissue loss volume estimates. Both general and specific indices of cognitive processes are normally distributed, with mean scores suggesting that a sizable proportion of both lesion groups is functioning within normal limits, while the pattern of results indicates the more persistent effects of left hemisphere lesions.

Table 2 reveals the association between the cognitive dependent variables and preinjury AFQT percentile score and the total brain-tissue loss volume. The most striking observation is that postinjury cognitive performance shows greater correlations with preinjury intelligence level than with volume of brain tissue lost. Left hemisphere tissue loss shows greater association with most cognitive measures than right hemisphere tissue loss; the exceptions are the WAIS Performance IQ, Block Design, and Spatial Rotation test scores.

\section{Regression Model 1}

The shared variance between the indices of brain damage we chose and cognitive performance was rather low in most cases. Figure 1 graphically displays the relative reliability of total braintissue loss volume or specific structure involvement within a 


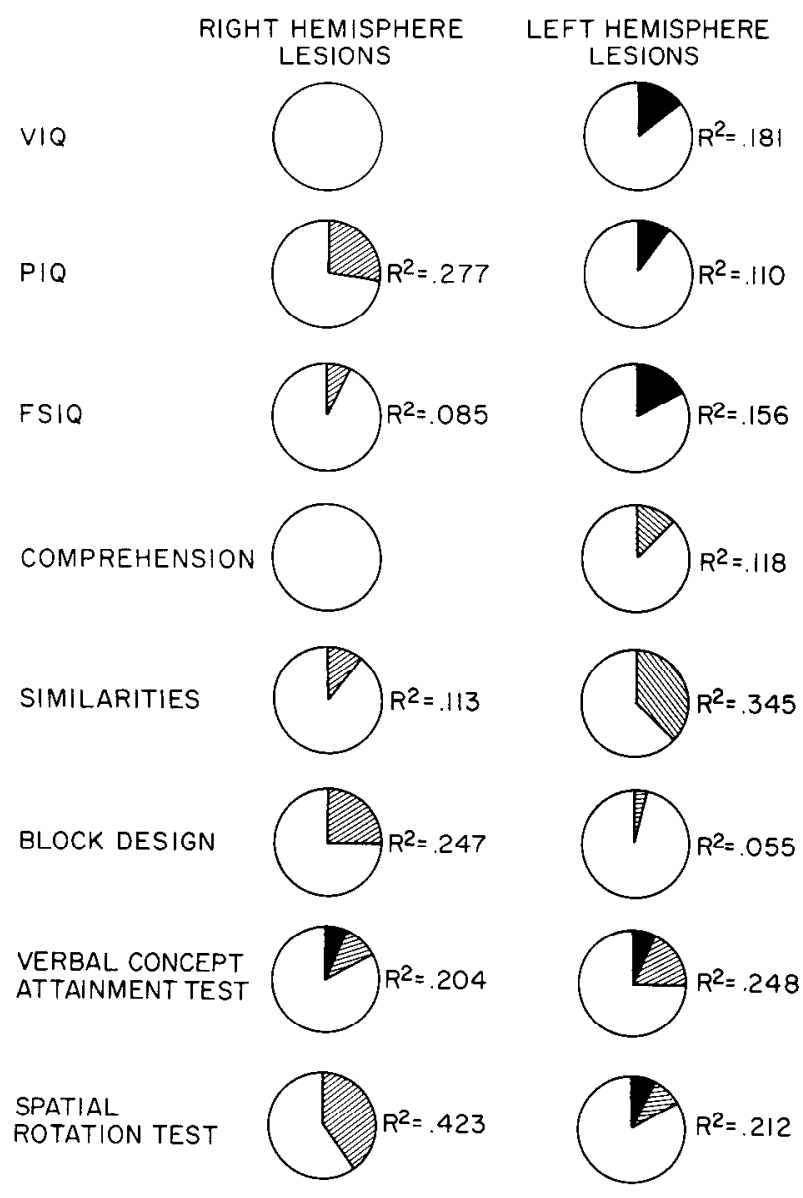

Figure 1. Regression Model 1. Graphic demonstration of the relative predictability of total brain-tissue loss volume $(\square)$ and particular brain structure lesions (凂) for postinjury test performance. The total area within each circle represents $100 \%$ of the variance in performance for each dependent measure. The shaded areas illustrate the relative proportions of variance in performance on each dependent variable that can be predicted by total brain-loss volume and particular structural loss. For example, on the Verbal Concept Attainment Test, total brainloss volume and particular structural loss contribute to predicting test performance in the final model. For patients with right hemisphere lesions, each predictor accounts for about half the variance, whereas for patients with left hemisphere lesions, particular structural loss is a relatively better predictor of postinjury performance.

hemisphere in predicting performance on a cognitive measure. In the right hemisphere lesion group, total brain-tissue loss volume plays a negligible role. On both "general" and "specific" cognitive measures, specific structural involvement is the best predictor of test scores following brain injury. When patients with left hemisphere lesions are considered, the picture is somewhat different. The only significant predictor on the general cognitive measures is total brain-tissue loss volume. For the specific cognitive measures, specific structural loss is either the best or the only significant predictor of test performance (see Tables 3 and 4). This relationship between brain damage and performance in left hemisphere lesion patients supports our hypotheses regarding the relative importance of structure loss and brain-tissue loss volume for predicting postinjury cognitive performance.

While the purpose of this study was not to delineate which specific brain structures, when damaged, are most predictive of impaired cognitive performance, some comment on the findings is necessary. In the right hemisphere lesion group, no structure was significantly associated with verbal IQ. Deep white matter lesions were most predictive of performance and full-scale IQ scores, emphasizing the likely importance of white matter disconnection/lesions in the persistence of general cognitive deficits (Geschwind, 1965). Structure association was absent or negligible in predicting performance on two specific verbal measures, the Comprehension and Similarities subtests of the WAIS. Performance on a verbal test of concept formation was interestingly predicted not only by total brain-tissue loss volume but by the involvement of two anterior structures, the insula and caudate head. Both frontal cortex involvement and deep white matter lesions predicted performance on the Block Design Test, whereas temporaloccipital and more mesial cortex lesions, as well as corpus callosum involvement, predicted performance on a spatial rotation test. The relationship between performance on these tests and the specific predictive structures was generally not surprising, although the predictability of verbal concept performance by involvement of right anterior structures is somewhat surprising.

As we have described, for patients with left hemisphere lesions, only brain-tissue loss volume was predictive of performance on the general measures of cognitive processing (i.e., the VIQ, PIQ, and FSIQ). For the specific verbal tests (i.e., comprehension, similarities, and VCAT), frontal and temporal cortex and underlying white matter lesions are most predictive of impaired performance. On the Block Design Test, temporal cortex predictability of performance is negligible, while for performance on the spatial rotation test, lesions to the temporal cortex and underlying white matter are most predictive of impaired performance-a not totally unexpected finding, given recent studies on the relationship between the posterior left hemisphere and image generation (e.g., see Farah, 1984).

Because of the generally low levels of predictability of impaired cognitive performance seen with specific brain structure involvement, these results must be considered suggestive at best.

We suspected that postinjury performance on most of the cognitive measures was highly dependent upon educational level and premorbid intelligence. Therefore, the addition of the preinjury Armed Forces Qualification Test (Uhlaner, 1968) percentile score as a covariate forced into the regression model should elevate the overall predictability of postinjury cognitive performance (i.e., in conjunction with brain-tissue loss volume and specific structural loss) to acceptable levels. The results of this addition are described below.

\section{Regression Model 2}

Figure 2 graphically displays the relative ability of total braintissue loss volume and specific structural involvement to predict performance on a cognitive measure when adjusted for (i.e., in the presence of) preinjury intelligence (AFQT percentile score). In this case, we find that preinjury intelligence is the best predictor of postinjury cognitive performance on almost all measures. For right hemisphere lesions, on only one cognitive measure (i.e., the VCAT) can total brain-tissue loss volume better predict performance than can specific structural involvement. For patients with left hemisphere lesions, the pattern of results of Model 2 is similar to that of Model 1, with the exception of the Comprehension and Block Design regression models, where total brain-tissue loss volume is now a better predictor of postinjury congitive performance than are particular brain structures, in the presence of the preinjury intelligence score. Unlike the results from Model 1, the degree of shared variance seen in Model 2 is fairly high, which can be explained by the addition of the preinjury intelligence estimate (see Tables 5 and 6).

\section{Discussion}

The following general conclusions appear justified on the basis of our results. We find that specific structural involvement is rclativcly morc important in predicting persistence of specific cognitive impairments following penetrating brain wounds than 
Table 3. Model 1: Right hemisphere lesions

\begin{tabular}{|c|c|c|c|c|c|}
\hline Test & Structure & $F$ & $p$ Value & $\begin{array}{l}\text { Variance } \\
\text { added to } \\
\text { model }\left(R^{2}\right)\end{array}$ & \\
\hline \multicolumn{6}{|l|}{ WAIS } \\
\hline Verbal IQ & - & - & - & - & \multirow{4}{*}{$0.277\left(\right.$ total $\left.R^{2}\right)$} \\
\hline \multirow[t]{3}{*}{ Performance IQ } & Cortical white matter & 15.76 & 0.0002 & 0.145 & \\
\hline & Temporal lobe white matter & 6.34 & 0.0138 & 0.087 & \\
\hline & Corpus callosum posterior $1 / 2$ & 5.05 & 0.0273 & 0.045 & \\
\hline Full-scale IQ & Cortical white matter & 8.00 & 0.0058 & 0.085 & \multirow{6}{*}{$0.247\left(\right.$ total $\left.R^{2}\right)$} \\
\hline Comprehension subtest & - & - & - & - & \\
\hline Similarities subtest & Insular cortex & 11.24 & 0.0012 & 0.113 & \\
\hline \multirow[t]{3}{*}{ Block Design subtest } & Cortical white matter & 13.44 & 0.0004 & 0.137 & \\
\hline & Corpus callosum posterior $1 / 2$ & 8.30 & 0.0051 & 0.066 & \\
\hline & Frontal lobe combined & 4.85 & 0.0305 & 0.044 & \\
\hline \multicolumn{6}{|l|}{ VCAT } \\
\hline & Brain-tissue volume loss & 11.64 & 0.0010 & 0.113 & \multirow{3}{*}{0.204 (total $\left.R^{2}\right)$} \\
\hline & Insular cortex & 6.78 & 0.0109 & 0.054 & \\
\hline & Caudate head & 4.00 & 0.0486 & 0.037 & \\
\hline \multicolumn{6}{|l|}{ Spatial Rotation Test } \\
\hline & Corpus callosum posterior $1 / 2$ & 13.83 & 0.0004 & 0.186 & \multirow{5}{*}{0.423 (total $R^{2}$ ) } \\
\hline & Mesial cortex combined & 12.17 & 0.0008 & 0.107 & \\
\hline & Temporal cortex combined & 11.28 & 0.0012 & 0.050 & \\
\hline & Temporaloccipital cortex & 7.63 & 0.0071 & 0.044 & \\
\hline & Thalamus & 4.87 & 0.0303 & 0.044 & \\
\hline
\end{tabular}

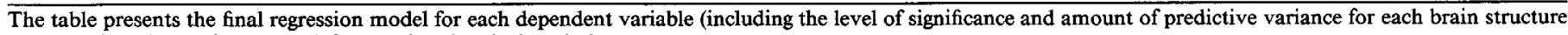
that remained in the final model) for the right hemisphere lesion group.

total brain-tissue loss volume. This is particularly the case for left hemisphere lesion patients. The performance of left hemisphere lesion patients on more general cognitive measures, however, is better predicted by total brain-tissue loss volume than particular structural loss. This finding cross-validates earlier re- search and supports our hypotheses regarding the relative importance of total brain-tissue loss volume and particular structural loss for persistence of cognitive deficits. Since we obscrved this primarily in left hemipshere lesion patients, we need to stress that our tests were selected on face-validity. It could be

Table 4. Model 1: Left hemisphere lesions

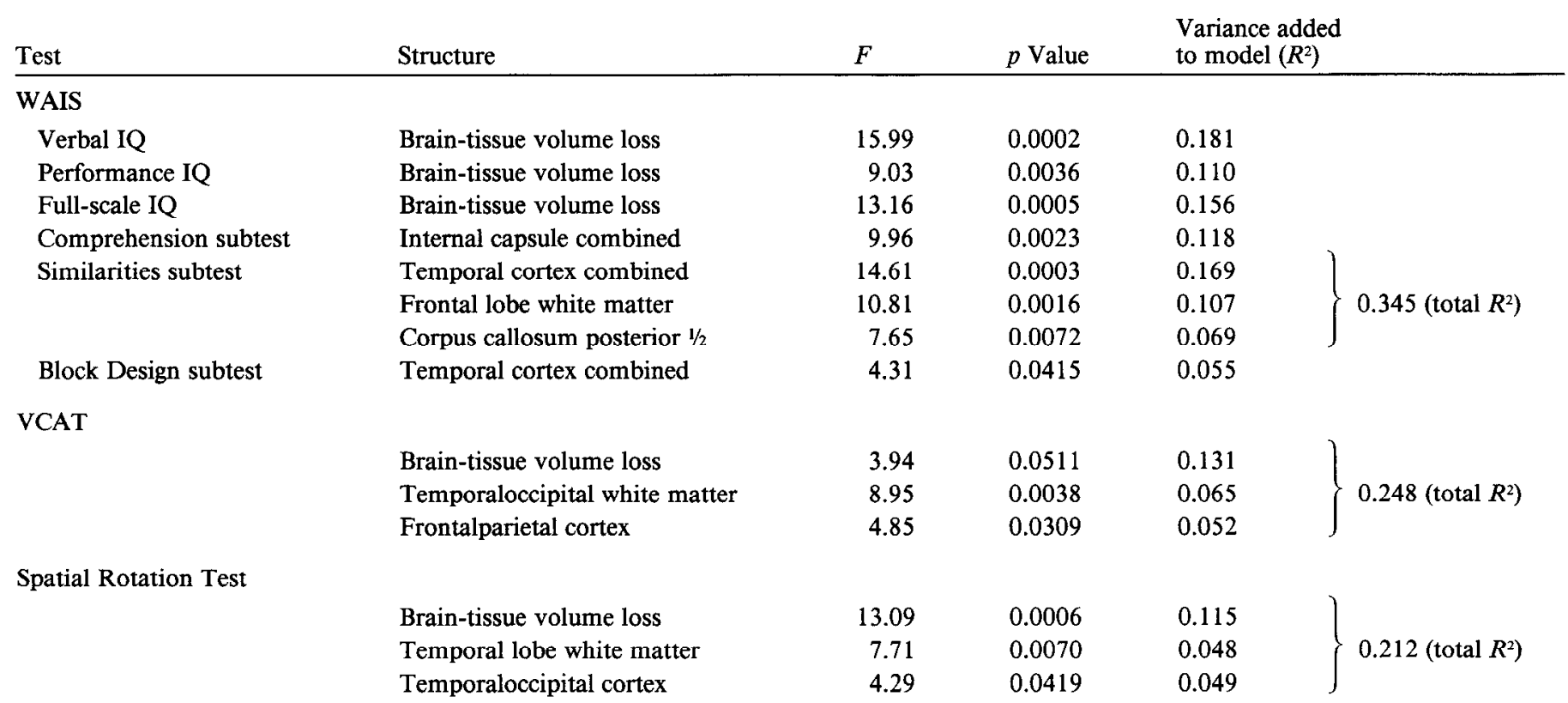




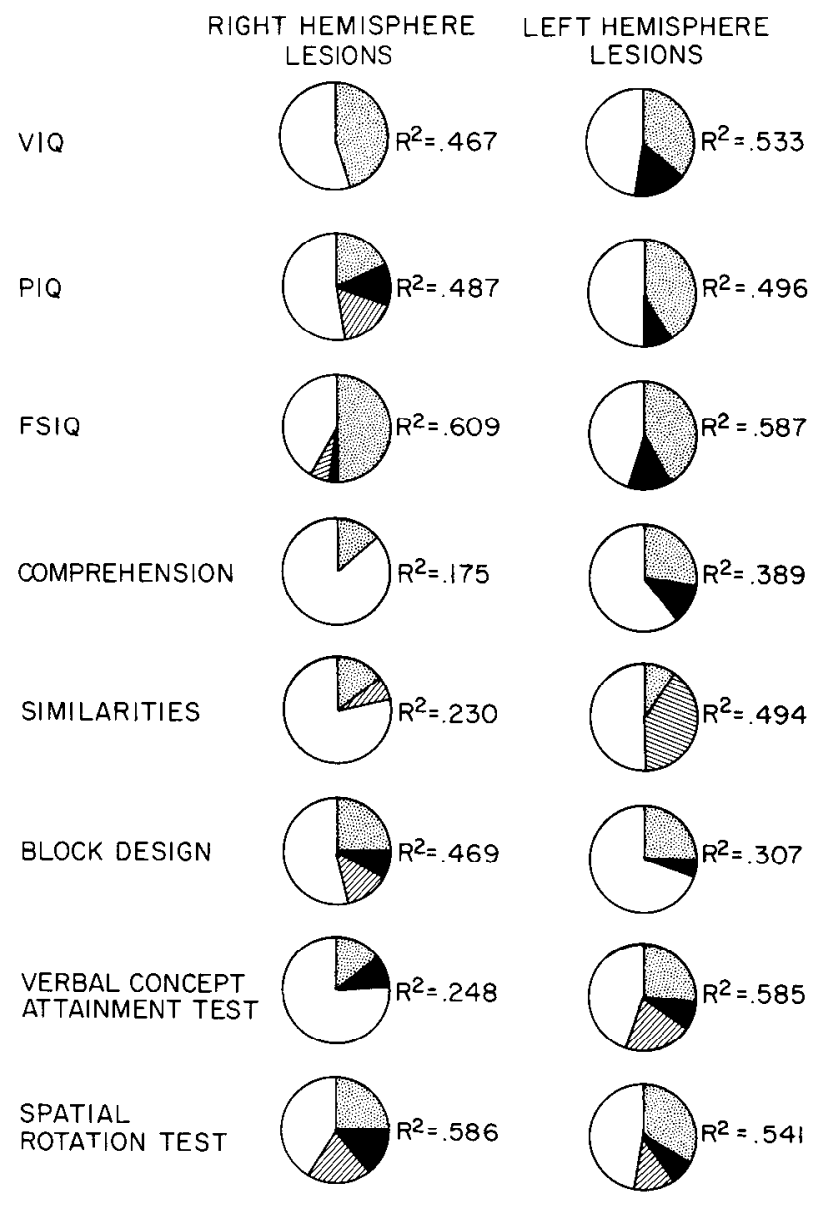

Figure 2. Regression Model 2. Graphic demonstration of the relative predictability of total brain-tissue loss volume $(\square)$ and particular brain structure lesions ( jury intelligence (AFQT) percentile score (圈) for postinjury test performance. The total area within each circle represents $100 \%$ of the variance in performance for each dependent measure. The shaded areas illustrate the relative proportions of variance in performance on each dependent variable that can be predicted by total brain-loss volume, particular structural loss, and preinjury AFQT percentile score. that the current results stem partially from our choice of tests (e.g., most require the retrieval of old verbal knowledge or learned procedures) and are not generalizable. This is an important consideration, given the difficulty in constructing tasks that might measure the kind of visual-spatial/auditory processes most effectively subserved by right hemisphere brain mechanisms. Another factor in assessing the significance of our results is the hypothetically strong positive correlation betwen number of specific brain structures involved and total brain-tissue loss volume. In this case, the predictive effects of a set of specific brain structures might be due to a statistical artifact merely reflecting the cumulative effects of a large lesion. However, unpublished results from the Vietnam Head Injury Study (VHIS) reveal only a modest positive association between total number of specific brain structures that predict postinjury cognitive performance and total brain-tissue loss volume. Similarly, deep brain structures could, in some cases, better predict postinjury cognitive performance than total brain-tissue loss volume, because their involvement could reflect a common brain structure end point for lesion paths that originated from separate and distant skull penetrations. However, in our studies, it was surface cortex and particularly underlying white matter involvement that appeared most critical for the persistence of specific cognitive deficits (see Geschwind, 1965, for further discussion of the role of white matter lesions in the persistence of cognitive deficit following brain injury).

Despite the emphasis of our study on brain lesions, it should be clear from the Model 2 regression analyses that the major predictor of persistence of cognitive deficits is preinjury intelligence/education. This finding suggests that preinjury intelligence/educational experience helps determine cognitive recovery and/or functional compensation for cognitive deficits and is relatively unaffected by focal lesions but is affected by large brain-tissue loss volume [or by left hemisphere brain lesions; Grafman et al. (unpublished observations) further discusses these issues].

It has been a long time since Lashley (1929) gave his last criticism of localizationist theory. More recent texts on neural plasticity and recovery of function (e.g., Singer and Stein, 1982; Porter and Fitzsimons, 1975; Rakic and Goldman-Rakic, 1982; Stein et al., 1974; Van Hof and Mohn, 1981) tend to emphasize specific, almost modular processes and their recovery in animals with brain lesions (Finger, 1978). Although the results from our

Table 5. Model 2: Right hemisphere lesions

\begin{tabular}{lllll} 
& & & & $\begin{array}{l}\text { Variance } \\
\text { shared by } \\
\text { preinjury } \\
\text { AFQT }\end{array}$ \\
Test & $F$ & & $\begin{array}{l}\text { Total } \\
\text { variance } \\
\left(R^{2}\right)\end{array}$ \\
\hline WAIS & & & & \\
$\quad$ Verbal IQ & 72.74 & 0.0001 & 0.467 & 0.467 \\
Performance IQ & 25.74 & 0.0001 & 0.243 & 0.487 \\
Full-scale IQ & 92.05 & 0.0001 & 0.531 & 0.609 \\
Comprehension subtest & 17.61 & 0.0001 & 0.175 & 0.175 \\
Similarities subtest & 13.33 & 0.0005 & 0.138 & 0.230 \\
Block Design subtest & 25.54 & 0.0001 & 0.241 & 0.469 \\
VCAT & 11.11 & 0.0013 & 0.120 & 0.248 \\
Spatial Rotation Test & 25.74 & 0.0001 & 0.250 & 0.586
\end{tabular}

The final regression model for each dependent variable, contrasting the proportion of postinjury test performance variance that can be predicted by preinjury intelligence (AFQT) with the predictability of the total model (for the right hemisphere lesion group).

${ }^{a}$ Adjusting for preinjury AFQT percentile score (AFQT is always in the model as a covariate).

${ }^{b}$ Preinjury AFQT percentile score + total brain-tissue loss volume + specific structural involvement (e.g., see Tables 3 and 4). 
Table 6. Model 2: Left hemisphere lesions

\begin{tabular}{lllll} 
& & & $\begin{array}{l}\text { Variance } \\
\text { shared by } \\
\text { preinjury } \\
\text { AFQT }^{a}\left(R^{2}\right)\end{array}$ & $\begin{array}{l}\text { Total } \\
\text { variance } \\
\left(R^{2}\right)\end{array}$ \\
\hline Test & $F$ & $p$ Value & & \\
$\quad$ WAIS & & & & 0.335 \\
$\quad$ Verbal IQ & 35.40 & 0.0001 & 0.372 & 0.496 \\
Performance IQ & 42.06 & 0.0001 & 0.372 & 0.587 \\
Full-scale IQ & 47.34 & 0.0001 & 0.406 & 0.389 \\
Comprehension subtest & 26.81 & 0.0001 & 0.271 & 0.494 \\
Similarities subtest & 15.28 & 0.0002 & 0.175 & 0.307 \\
Block Design subtest & 22.69 & 0.0001 & 0.242 & 0.585 \\
VCAT & 28.47 & 0.0001 & 0.289 & 0.541 \\
Spatial Rotation Test & 39.95 & 0.0001 & 0.363 & \\
\hline
\end{tabular}

The final regression model for each dependent variable, contrasting the proportion of postinjury test performance variance that can be predicted by preinjury intelligence (AFQT) with the predictability of the total model (for the left hemisphere lesion group).

${ }^{a}$ Adjusting for preinjury AFQT percentile score (AFQT is always in the model as a covariate).

${ }^{b}$ Preinjury AFQT percentile score + total brain-tissue loss volume + specific structural involvement (e.g., see Tables 3 and 4).

study may seem intuitively obvious, the study offers empirical evidence from human lesions that complements earlier research (Newcombe, 1969) that suggested that a modular approach to examining the persistence of cognitive deficits following brain injury would prove beneficial.

In summary, we find that brain-tissue loss volume inhibits recovery of general cognitive processes (probably because of the lack of remaining tissue to assume compensatory processing), while particular structural loss inhibits recovery of specific cognitive processes [but may allow for the use of compensatory cognitive processes subserved by noninvolved cortical tissue (Lund, 1978) to help patients perform on a general cognitive task]. Nevertheless, preinjury intelligence/education appears to play a larger role in predicting persistence of cognitive deficit than either total brain-tissue loss volume or particular structural loss.

\section{References}

Black, F. W. (1974) Cognitive effects of unilateral brain lesions secondary to penetrating missile wounds. Percept. Mot. Skills 38: 387391.

Corkin, S. (1979) Hidden figures test performance: Lasting effects of unilateral penetrating head injury and transient effects of bilateral cingueotomy. Neuropsychologia 17: 585-605.

Cotman, C. W., and M. Nieto-Sampedro (1982) Brain function, synapse renewal, and plasticity. Ann. Rev. Psychol. 33: 371-401.

Eidelberg, E., and D. G. Stein (eds.) (1974) Functional recovery after lesions of the nervous system. Neurosci. Res. Prog. Bull. 12: 191303.

Farah, M. (1984) The neurological basis of mental imagery: A componential analysis. Cognition 18: 245-272.

Finger, S. (ed.) (1978) Recovery from Brain Damage: Research and Theory, Plenum, New York.

Finger, S., and D. G. Stein (1982) Brain Damage and Recovery: Research and Clinical Perspectives, Academic, New York.

Geschwind, N. (1965) Disconnexion syndromes in animals and man. Brain 88: 237-291 (Pt. I); 585-644 (Pt. II).

Lashley, K. S. (1963) Brain Mechanisms and Intelligence, Dover, New York.

LeVere, T. (1975) Neural stability, sparing, and behavioral recovery following brain damage. Psychol. Rev. 82: 344-358.

Lund, R. D. (1978) Development and Plasticity of the Brain, Oxford, London.

Matarazzo, J. D. (1972) Wechsler's Measurement and Appraisal of Adult Intelligence, Williams and Wilkins, Baltimore, MD.
Matthews, C. G. (1977) Adult (C.A.) 15 and Older: Neuropsychological Test Battery, pp. 1-32, published by author, Madison, WI.

Meyer, D. R., and Meyer, P. M. (1977) Dynamics and bases of recoveries of functions after injuries to the cerebral cortex. Physiol. Psychol. 5: 133-165.

Nakamura, K. K., and M. S. Gazzaniga (1978) Hemispherectomy versus commissurotomy in the monkey: One hemisphere can be better than two. Exp. Neurol. 59: 202-208.

Newcombe, F. (1969) Missile Wounds of the Brain, Oxford, London. Porter, R., and D. W. Fitzsimons (eds.) (1975) Outcome of Severe Damage to the Central Nervous System, Elsevier, Amsterdam.

Rakic, P., and P. S. Goldman-Rakic (eds.) (1982) Development and modifiability of the cerebral cortex. Neurosci. Res. Prog. Bull. 20: 429-611.

Stein, D. G., J. J. Rosen, and N. Butters (1974) Plasticity and Recovery of Function in the Central Nervous System, Academic, New York.

Teuber, H.-L. (1959) Some alterations in behavior after cerebral lesions in man. In The Evolution of Nervous Control from Primitive Organisms to Man, American Association for the Advancement of Science, Washington, DC.

Teuber, H.-L. (1960) The premorbid personality and reaction to brain damage. Am. J. Orthopsychiatry 30:322-329.

Teuber, H.-L., and R. S. Liebert (1958) Specific and general effects of brain injury in man. Arch. Neurol. Psychiatry 80: 403-407.

Teuber, H.-L., and S. Weinstein (1956) Ability to discover hidden figures after cerebral lesions. Arch. Neurol. Psychiatry 76: 369-379.

Teuber, H.-L., W. S. Battersby, and M. B. Bender (1952) Effects of cerebral lesions on intellectual functioning in man. Fed. Proc. 11: 161.

Thompson, R. F., T. W. Berger, and J. Madden IV (1983) Cellular processes of learning and memory in the mammalian CNS. Ann. Rev. Neurosci. 6: 447-491.

Uhlaner, J. E. (1968) Development of Armed Forces Qualification Test and Predecessor Army Screening Tests, 1946-1950, Army Personnel Research Branch Report 976, Department of Defense, Washington, DC.

Vandenberg, S. G., and A. R. Kuse (1978) Mental rotations, a group test of three-dimensional spatial visualization. Percept. Mot. Skills 47: 599-604.

Van Hof, M. W., and G. Mohn (eds.) (1981) Functional Recovery from Brain Damage, Elsevier/North Holland, Amsterdam.

Wechsler, D. (1955) Manual for the Wechsler Adult Intelligence Scale, Psychological Corporation, New York.

Weinstein, S., and H.-L. Teuber (1957a) The role of preinjury education and intelligence level in intcllcctual loss after brain injury. $J$. Comp. Physiol. Psychol. 50: 535-539.

Weinstein, S., and H.-L. Teuber (1957b) Effects of penetrating brain injury on intelligence test scores. Science $125: 1036-1037$. 